\title{
Mammalian short palate lung and nasal epithelial clone 1 (SPLUNC1) in pH-dependent airway hydration ${ }^{\star}$
}

\author{
Robert Tarran ${ }^{a},{ }^{*}$ and Matthew R. Redinbo ${ }^{b, c, d}$ \\ ${ }^{a}$ Cystic Fibrosis/Pulmonary Research and Treatment Center, Department of Cell Biology and \\ Physiology, University of North Carolina, Chapel Hill, NC 27599, USA \\ bDepartment of Chemistry, University of North Carolina, Chapel Hill, NC 27599, USA \\ 'Department of Biochemistry and Biophysics, University of North Carolina, Chapel Hill, NC 27599, \\ USA
}

dDepartment of Microbiology and Immunology, University of North Carolina, Chapel Hill, NC 27599, USA

\begin{abstract}
The epithelia that line the conducting airways are the lung's first point of contact with inhaled pathogens and toxicants. As such, they are known to play an important role in the lung's innate defense system, which includes (i) the production of airway surface liquid (ASL) that helps cleanse the airways through the physical removal of pathogens and toxicants on the mucociliary escalator and (ii) the secretion of anti-microbial proteins into the ASL to kill inhaled pathogens. Interestingly, the recently crystallized short palate lung and nasal epithelial clone 1 (SPLUNC1) protein appears to be a multi-functional protein. That is, it not only acts as an anti-microbial agent, but also modulates ASL homeostasis by acting as an endogenous inhibitor of the epithelial $\mathrm{Na}^{+}$ channel $(\mathrm{ENaC})$. This review will focus on the latter function of SPLUNC1, and will discuss new structural and physiological data regarding SPLUNC1's failure to function as a regulator of ASL hydration in CF airways.
\end{abstract}

\section{Keywords}

Airway epithelia; BPIFA1; Cystic fibrosis; PLUNC; ENaC

\section{Introduction}

\begin{abstract}
Human, short palate lung and nasal epithelial clone 1 (SPLUNC1) is a 256 amino acid secreted protein that is highly expressed in airway epithelia (Di, 2011). SPLUNC1 nomenclature has varied since it was first discovered. Originally it was termed PLUNC (Weston et al., 1999), however, the "short" prefix was later added as it became part of a family of long and short PLUNCs (Bingle and Craven, 2002). Subsequently, based its
\end{abstract}

\footnotetext{
This article is part of a Directed Issue entitled: Cystic Fibrosis: From o-mics to cell biology, physiology, and therapeutic advances. (c) 2014 Elsevier Ltd. All rights reserved.

*Corresponding author. Tel.: +1 919966 7052. robert_tarran@med.unc.edu (R. Tarran), redinbo@unc.edu (M.R. Redinbo).
} 
structural homology to bacterial permeability increasing protein (BPI), an archetypal antimicrobial factor, it was also named BPIFA1 (BPI-family member A1). To further complicate matters, SPLUNC1 has also been referred to as LUNg specific protein-X (LUNX) (Iwao et al., 2001), nasopharyngeal carcinoma-related protein (NASG) (Zhang et al., 2003) and secreted protein from upper respiratory tract (SPURT) (Di et al., 2003). Regardless of name, SPLUNC1 is thought to play an important role in lung innate defense through a number of different means. SPLUNC1 has been shown to have anti-bacterial activity against Klebsiella pneumonia, Mycoplasma pneumoniae, Pseudomonas aeruginosa, and Staphylococcus aureus (Gally et al., 2011), as well as anti-viral activity (Epstein-Barr virus) (Zhou et al., 2008). Additionally, SPLUNC1 can regulate ion/mucus transport and hydration levels in the lung (Gaillard et al., 2010), lower surface tension through its surfactant-like properties (Bartlett et al., 2011), and act as an inflammatory mediator (Di, 2011). In general, there is little mechanistic data available regarding how SPLUNC1 performs these functions. But, in light of SPLUNC1's recently determined crystal structure, some insights have been gained. This review will focus on how these molecular details relate to SPLUNC1's ability to regulate ion transport in normal and cystic fibrosis (CF) airways by acting as an endogenous inhibitor of the epithelial $\mathrm{Na}^{+}$channel $(\mathrm{ENaC})$.

\section{The epithelial sodium channel (ENaC)}

$\mathrm{ENaC}$ is a heterotrimer that consists of $\alpha, \beta$, and $\gamma$ subunits (Rossier and Stutts, 2008). Each subunit contains intracellular $\mathrm{N}$-and $\mathrm{C}$-termini, two transmembrane spanning domains, and a large extracellular loop. The extracellular loops of the $a$ and $\gamma \mathrm{ENaC}$ subunits can be proteolytically cleaved at multiple sites by many types of proteases including furin-type convertases, trypsin-like serine proteases, neutrophil elastase, and acid proteases, leading to activation of the channel and increased $\mathrm{Na}^{+}$absorption (Rossier and Stutts, 2008; Hughey et al., 2007; Alli et al., 2012). Both trypsin-like proteases (e.g., prostasin) and acid proteases (e.g., cathepsin B) are secreted by airway epithelia into the ASL (Kesimer et al., 2009), so there is a wide variety of proteases that can activate ENaC. Furthermore, during times of inflammation, neutrophil-derived proteases such as neutrophil elastase are also secreted into the ASL and may additionally cleave ENaC (Caldwell et al., 2005). Indeed, it has been proposed that excessive protease activity seen in CF sputum contributes to abnormal regulation of $\mathrm{ENaC}$ in $\mathrm{CF}$ airways (Caldwell et al., 2005).

Whilst proteolysis of ENaC has been well described (Hughey et al., 2007; Rossier and Stutts, 2008), little is known regarding how proteolysis $\mathrm{ENaC}$ is regulated by airway epithelia. However, we recently identified SPLUNC1 as a potent inhibitor of ENaC that is secreted into the ASL where it binds extracellularly to $\mathrm{ENaC}$ and prevents it from being proteolytically cleaved/activated (Garcia-Caballero et al., 2009; Garland et al., 2013; Hobbs et al., 2013). We have yet to perform single channel analysis of ENaC \pm SPLUNC1.

However, our data suggest that SPLUNC1 most likely reduces the number of ENaCs in the plasma membrane (Rollins et al., 2010). Furthermore, while we cannot yet rule out additional effects of SPLUNC1 on the open probability of ENaC, the slow onset of inhibition ( $45 \mathrm{~min}$ in human bronchial airway epithelial cultures; HBECs) is more consistent with an effect on channel number than channel gating (Hobbs et al., 2013). 


\section{The mucus clearance component of the lung's innate defense system}

It has been estimated that the number of airborne bacteria may vary as dramatically as $\sim 200$ bacteria $/ \mathrm{m}^{3}$ of air in an office building to $\sim 700,000$ bacteria $/ \mathrm{m}^{3}$ of air in a slaughter house (Andersen, 1977). Despite these variations, by the time air reaches the alveolar region of a healthy lung it has been sterilized and humidified. The ASL lining the conducting airways helps ensure this by continuously moving up the airways, either by ciliary beating and/or cough clearance, until being swallowed or expectorated. As such, ASL is the first point of contact with inhaled pathogens. ASL is approximately isotonic with plasma (Knowles et al., 1997) and contains over 100 proteins including proteases and their inhibitors, mucins, and anti-microbial peptides, such as lysosome and SPLUNC1 (Kesimer et al., 2009; Casado et al., 2005). ASL consists of a $\sim 7 \mu \mathrm{m}$ periciliarly liquid layer with an overlying mucus layer. The periciliarly liquid layer bathes the cilia and acts as a lubricant that facilitates mucus clearance. Mucus is a non-Newtonian fluid whose physical properties are largely determined by the presence of gel-forming mucins such as MUC5AC and MUC5B (Fahy and Dickey, 2010). Mucus hydration has a large effect on its ability to be cleared by the underlying epithelia (Button et al., 2012; Tarran et al., 2001a). Thus, the better hydrated the ASL; the better mucus can be cleared. This is illustrated by the genetic disease pseudohypoaldosteronism (PHA), where ENaC activity is severely diminished. In these patients, the lungs are very well hydrated due to the lack of ENaC-led $\mathrm{Na}^{+} / \mathrm{ASL}$ absorption; consequently, mucus clearance rates are much greater than those seen in normal airways (Kerem et al., 1999).

\section{SPLUNC1 and airway surface liquid hydration}

We have previously shown that normal HBECs can autoregulate ion transport and ASL height in order to preserve mucus transport rates (Matsui et al., 1998; Tarran et al., 2001a, 2001b). In large part, this homeostasis is mediated by SPLUNC1, which acts as an autocrine, negative regulator of ENaC (Garcia-Caballero et al., 2009). For example, when SPLUNC1 was stably knocked down by shRNA, normal HBECs failed to regulate ENaC activity leading to ASL dehydration (Garcia-Caballero et al., 2009). When recombinant SPLUNC1 was added to the ASL, ENaC inhibition and ASL homeostasis were restored, suggesting that extracellular SPLUNC1 is sufficient to regulate ENaC (Garcia-Caballero et al., 2009). Interestingly, this function of SPLUNC1 is not exclusive to the lung: $\mathrm{ENaC}$ also regulates $\mathrm{Na}^{+}$absorption and mucus hydration/clearance in the auditory canal (Kim and Marcus, 2011); and knockdown of SPLUNC1 in the chinchilla inner ear causes a failure of mucus clearance in this organ (McGillivary and Bakaletz, 2010), which is consistent with a lack of SPLUNC1 causing ENaC hyperactivity.

SPLUNC1 is not a rapid inhibitor of $\mathrm{ENaC}$ and takes about $45 \mathrm{~min}$ to take full effect (Garcia-Caballero et al., 2009). Mucus clearance normally occurs at a rate of $10 \mathrm{~mm} / \mathrm{min}$ (Feng et al., 1999), therefore, it is unlikely that SPLUNC1 exerts minute-to minute changes in mucus clearance rates via ENaC. However, SPLUNC1 may also indirectly regulate chloride/ASL secretion by modulating the apical membrane potential: Since the ASL chloride concentration is approximately fourfold greater than the intracellular chloride concentration, there is no chemical gradient for chloride secretion (Boucher, 1994). 
However, inhibition of ENaC hyperpolarizes the apical membrane and provides an electrical driving force for chloride secretion (Boucher, 1994). Consistent with these observations, we have shown that the degree of ENaC activity greatly influences the ability of HBECs to secrete chloride and ASL (Tarran et al., 2006). That is, when ENaC is inhibited, the cystic fibrosis conductance regulator (CFTR) chloride channel can induce chloride/ASL secretion; and when $\mathrm{ENaC}$ is active, the apical plasma membrane is depolarized and there is no electrical gradient for CFTR-mediated $\mathrm{Cl}^{-} / \mathrm{ASL}$ secretion. We therefore propose that SPLUNC1 sets the level of ENaC activity, which in addition to regulating absorption rates, also determines how effective chloride will be at driving ASL secretion. Of note, when $\mathrm{ENaC}$ is inhibited, the onset of chloride/ASL secretion is very rapid and can occur within 60 s, which may allow for fine-tuning of ASL volume (Tarran et al., 2001b).

\section{SPLUNC1 and CF lung disease}

The lungs of patients with CF are typified by the accumulation of dehydrated, viscous mucus on airway surfaces, leading to bronchiolar occlusion and bacterial infection (Chmiel and Davis, 2003; Gibson et al., 2003). However, the primary genetic defect in CF is dysfunction of the CFTR chloride channel (Welsh and Smith, 1993), and a long-term challenge has been to reconcile knowledge of this genetic defect with clinical observations from affected lungs (e.g., sodium hyperabsorption, mucus accumulation, chronic inflammation, neutrophilia, and bronchiectasis). It has been proposed that the CFTR is itself a negative regulator of $\mathrm{ENaC}$ and that the initiating event in $\mathrm{CF}$ lung disease is depletion of the ASL due to chloride hyposecretion and sodium hyperabsorption, the combination of which causes dehydrated mucus to adhere to airway surfaces, preventing mucus clearance (Knowles and Boucher, 2002). This lack of clearance allows concentrated mucus plaques to accumulate until the airways become occluded and are colonized by bacteria. Following bacterial colonization, macrophages and neutrophils attempt to infiltrate the mucus plaques and attack the bacteria, but are excluded as a consequence of the increased mucus viscosity. Despite being unable to reach the bacteria, these immune cells still release their contents, including neutrophil elastase, causing a vicious cycle of infection, inflammation, and tissue damage (Chmiel and Davis, 2003; Gibson et al., 2003; Worlitzsch et al., 2002). ENaC hyperactivity contributes to the dehydration of ASL volume by removing both $\mathrm{Na}^{+}$ions and water molecules. This in turn may contribute to mucus stasis and an increased incidence of airway infections that frequently lead to patient death. Similar lung disease has been demonstrated in vivo in a transgenic murine model overexpressing ENaC, thus linking sodium hyperabsorption, volume depletion, and inflammation (Mall et al., 2004).

Whilst the mechanism underlying sodium hyperabsorption in CF airways is not fully understood, $\mathrm{CF} \mathrm{ENaC}$ is abnormally hyperactive due in part to its excessive proteolytic cleavage, indicating that $\mathrm{CF}$ ENaC may be in a more active state (Boucher et al., 1986; Gentzsch et al., 2010). Curiously, this increase in ENaC activity takes place in the face of elevated SPLUNC1 expression, which suggests that SPLUNC1 is non-functional in CF airways (Roxo-Rosa et al., 2006; Bingle et al., 2007). SPLUNC1 can be detected in CF HBECs (Garland et al., 2013). However, these cultures fail to autoregulate ASL height, suggesting that SPLUNC1 is non-functional in CF airways (Matsui et al., 1998). Because SPLUNC1-ENaC interactions are extracellular, and because $\mathrm{CF}$ ENaC is still responsive to 
protease inhibitors such as aprotinin (Donaldson et al., 2002; Tarran et al., 2006), we hypothesize that the altered CF ASL microenvironment prevents interactions between ENaC and SPLUNC1. Indeed, CF ASL has a lower $\mathrm{pH}$ than normal ASL due to the lack of bicarbonate secretion through CFTR (Coakley et al., 2003; Cho et al., 2011; Garland et al., 2013; Poulsen et al., 1994). Further analysis revealed that SPLUNC1's ability to bind to $\mathrm{ENaC}$-expressing epithelia, and its ability to inhibit $\mathrm{ENaC}$ was strongly $\mathrm{pH}$-dependent over the physiological range (i.e., pH 6.0-7.0) and were inhibited by acid pH (Garland et al., 2013). Thus, the failure of SPLUNC1 to bind and inhibit CF ENaC was not due to the lack of CFTR per se, but rather to the failure of CFTR to regulate ASL pH to appropriate levels. We found that increasing CF ASL $\mathrm{pH}$ toward normal levels restored SPLUNC1 function (i.e., CF ENaC was inactivated) and CF ASL hydration levels were increased (Garland et al., 2013). Thus, we propose that CFTR indirectly regulates SPLUNC1-ENaC interactions via its secretion of bicarbonate and the subsequent buffering of ASL pH into the neutral range favors SPLUNC1 binding.

\section{Structure of SPLUNC1}

We have recently resolved the crystal structure of human SPLUNC1 to $2.8 \AA$ resolution, and refined the structure to a final model that included residues 43-254 of the 256 amino acid protein (Garland et al., 2013) (Fig. 1). SPLUNC1 shares structural homology with the Nterminal half of the larger, human bacterial permeability increasing (BPI) protein (Beamer et al., 1997). The region in BPI where lipopolysaccharide (LPS) binds, a central cavity within this protective protein, is gated/occluded in SPLUNC1 by a C-terminal helix (a6) that is unique to SPLUNC1 and not seen in BPI (Fig. 1B). Still, the hydrophobic nature of the residues surrounding the internal, LPS-binding cavity of BPI is largely retained in SPLUNC1, suggesting that with the correct conformational change SPLUNC1 could bind to a large hydrophobic ligand like LPS. Despite these similarities, SPLUNC1 is clearly a unique molecule. Not only is it half the size of BPI, but it also possesses unique structural elements. For example, SPLUNC1 contains a leader peptide, residues 1-19 (not retained in the construct used for crystallization), followed by an 18 residue domain (G22-A39) we termed the "S18 region" that is not present in BPI or other BPI-type proteins (Garland et al., 2013). An 18 amino acid peptide based on this sequence failed to show any structure by circular dichroism (Hobbs et al., 2013); and unfortunately, despite the fact that this region was present in the 20-256 residue construct used for crystallization, this region was disordered in the resolved structure and could not be visualized within the electron density maps (Garland et al., 2013). This was one of two loop regions not observed in this $2.8 \AA$ resolution structure, the other being an 11-residue stretch comprised of amino acids 78-88 (Fig. 1B).

\section{Structural insights into SPLUNC1's pH-dependency}

In contrast to SPLUNC1, which fails to function in CF HBECs (Garland et al., 2013), a peptide corresponding to SPLUNC1's ENaC inhibitory domain/S18 region (Fig. 1A) inhibited ENaC-led ASL volume depletion equally well in both normal and CF HBECs (Hobbs et al., 2013). Further experiments revealed that this S18 peptide was $\mathrm{pH}$-independent and that only the complete SPLUNC1 molecule is pH-dependent (Garland et al., 2013). The 
resolved structure of SPLUNC1 (the first of this factor family from the mammalian lung) provided key information regarding the ability of intact SPLUNC1 to regulate the activity of $\mathrm{ENaC}$ in a pH-dependent manner. We identified a patch of electrostatic residues on the surface of SPLUNC1, including Asp-112, Lys-138, Arg152, and Asp-193 that, when disrupted by targeted mutations to alter their ionic character, significantly impacted SPLUNC1's ability to bind ENaC and regulate ASL height (Garland et al., 2013). For example, the mutation of either Arg-152-Glu or Asp-193-Asn eliminated the pH-dependent regulation of ENaC by SPLUNC1, causing SPLUNC1 to inhibit ENaC equally well regardless of $\mathrm{pH}$ and restored the ability of $\mathrm{ENaC}$ to regulate $\mathrm{ASL}$ homeostasis in $\mathrm{CF}$ HBECs. Importantly, when the electrostatic character of these two residues are returned, but their positions swapped as in a Arg-152-Asp/Asp-193-Arg double mutation, SPLUNC1 returns to functioning normally as a $\mathrm{pH}$-dependent binder and regulator of $\mathrm{ENaC}$ (Garland et al., 2013). These results support the conclusion that the electrostatic surface character of SPLUNC1 plays an important role in ENaC/ASL height homeostasis. Indeed, of the 35 surface-exposed electrostatic residues on human SPLUNC1, more than three-quarters are conserved in SPLUNC1's known sequence, including its five histidines (Fig. 2A and B). Typically, electrostatic amino acids like Asp, Glu, Lys, Arg, and His found on protein surfaces demonstrate less conservation of identity, as they only assist in the general solubility of globular proteins. Thus, the conservation of these residues in SPLUNC1 is notable and suggests that evolutionary pressure is in place to maintain them, perhaps by assisting in the proper $\mathrm{pH}$-dependent regulation of $\mathrm{ENaC}$.

\section{Strategies for restoring proper ENaC regulation in $\mathrm{CF}$ airways}

Taken together, our data suggest that it may be possible to restore proper ENaC regulation and lung hydration by either increasing CF ASL pH (and thus restoring native SPLUNC1 function) or by adding a peptide of SPLUNC1's ENaC inhibitory domain. However, since SPLUNC1 is degraded by neutrophil elastase a highly abundant protease in CF sputum, CF SPLUNC1 may be degraded and nonfunctional (Jiang et al., 2013; Delacourt et al., 2002; Konstan et al., 1994). If this is the case, then raising ASL $\mathrm{pH}$ may not restore SPLUNC1 function in $\mathrm{CF}$ airways, suggesting that the addition of a recombinant peptide may be a more favorable treatment option. To the best of our knowledge, the degree of degradation of SPLUNC1 protein has not been ascertained in sputum from CF patients. However, peptides corresponding to the G22-A39 region were detectable in sputum from normal but not CF subjects (Hobbs et al., 2013), suggesting that abnormal SPLUNC1 degradation occurs in CF lungs. Clearly, more experiments will be required to evaluate SPLUNC1 function in CF patients, especially now that we know that fragments of SPLUNC1 may retain biological activity when removed from the SPLUNC1 protein (Hobbs et al., 2013).

\section{Model of pH dependent SPLUNC1 function}

Together, our functional and structural data support a model wherein SPLUNC1 serves to plug the operational ENaC "drain" that removes sodium ions and water from the ASL overlying airway epithelia (Fig. 3). At normal pH in healthy lungs (NL), SPLUNC1 can effectively contact ENaC and prevent the proteolytic activation of this channel. The proper ASL height allows cilia to function, and to beat appropriately to move mucous and bacterial 
pathogens away from the epithelia surface. Importantly, the $\mathrm{pH}$ is decreased relative to healthy ASL and it would appear that $\mathrm{pH}$ alone is sufficient to disrupt SPLUNC1's contact with $\mathrm{ENaC}$, allowing $\mathrm{ENaC}$ to remove $\mathrm{Na}^{+}$ions and water, leading to ASL dehydration and trapped cilia that are unable to mobilize either mucous or pathogenic cells (Garland et al., 2013) (Fig. 3). This hypothesis is supported by our data demonstrating that elevation of CF ASL $\mathrm{pH}$ prevents cleavage of $\mathrm{ENaC}$ and restores ASL volume homeostasis (Garland et al., 2013). Importantly, the pH sensitivity of ENaC is lost when SPLUNC1 is stably knocked down by shRNA (Garland et al., 2013). We have found that the adjustment of ASL pH does not improve the ability of the $\mathrm{S} 18$ peptide to regulate $\mathrm{ENaC}$, indicating that the complete SPLUNC1 molecule appears essential in pH-dependent ENaC control.

\section{Conclusions}

As we mentioned at the start of this review, SPLUNC1 is a multifunctional protein that impacts several aspects of innate defense of the lung, which we are only beginning to understand. Looking beyond $\mathrm{ENaC}$ regulation, it will be interesting to see whether the crystal structure of SPLUNC1 will help determine the molecular basis for its other functions.

\section{Acknowledgments}

RT and MRR were funded by NIH HL108927. We thank Mr. Shawn Terryah for editing of this review, and our colleagues in both the CF Center and the Department of Chemistry for insightful discussion regarding CF lung disease.

\section{References}

Alli AA, Song JZ, Al-Khalili O, Bao HF, Ma HP, Eaton DC. Cathepsin B is secreted apically from Xenopus 2F3 cells and cleaves the epithelial sodium channel (ENaC) to increase its activity. J Biol Chem. 2012; 287:30073-30083. [PubMed: 22782900]

Andersen, I.; Proctor, D., editors. Respiratory defense mechanisms. New York: Marcel Dekker; 1977. p. 49

Bartlett JA, Gakhar L, Penterman J, Singh PK, Mallampalli RK, Porter E, et al. PLUNC: a multifunctional surfactant of the airways. Biochem Soc Trans. 2011; 39:1012-1016. [PubMed: 21787339]

Beamer LJ, Carroll SF, Eisenberg D. Crystal structure of human BPI and two bound phospholipids at 2.4 angstrom resolution. Science. 1997; 276:1861-1864. [PubMed: 9188532]

Bingle CD, Craven CJ. PLUNC: a novel family of candidate host defence proteins expressed in the upper airways and nasopharynx. Hum Mol Genet. 2002; 11:937-943. [PubMed: 11971875]

Bingle L, Barnes FA, Cross SS, Rassl D, Wallace WA, Campos MA, et al. Differential epithelial expression of the putative innate immune molecule SPLUNC1 in cystic fibrosis. Respir Res. 2007; 8:79. [PubMed: 17988392]

Boucher RC. Human airway ion transport: Part one. Am J Respir Crit Care Med. 1994; 150:271-281. [PubMed: 8025763]

Boucher RC, Stutts MJ, Knowles MR, Cantley L, Gatzy JT. Na+ transport in cystic fibrosis respiratory epithelia. Abnormal basal rate and response to adenylate cyclase activation. J Clin Invest. 1986; 78:1245-1252. [PubMed: 3771796]

Button B, Cai LH, Ehre C, Kesimer M, Hill DB, Sheehan JK, et al. A periciliary brush promotes the lung health by separating the mucus layer from airway epithelia. Science. 2012; 337:937-941. [PubMed: 22923574] 
Caldwell RA, Boucher RC, Stutts MJ. Neutrophil elastase activates near-silent epithelial Na+ channels and increases airway epithelial Na+ transport. Am J Physiol Lung Cell Mol Physiol. 2005; 288:L813-L819. [PubMed: 15640288]

Casado B, Pannell LK, Iadarola P, Baraniuk JN. Identification of human nasal mucous proteins using proteomics. Proteomics. 2005; 5:2949-2959. [PubMed: 15996010]

Chmiel JF, Davis PB. State of the art: why do the lungs of patients with cystic fibrosis become infected and why can't they clear the infection? Respir Res. 2003; 4:8. [PubMed: 14511398]

Cho DY, Hwang PH, Illek B, Fischer H. Acid and base secretion in freshly excised nasal tissue from cystic fibrosis patients with DeltaF508 mutation. Int Forum Allergy Rhinol. 2011; 1:123-127. [PubMed: 22034590]

Coakley RD, Grubb BR, Paradiso AM, Gatzy JT, Johnson LG, Kreda SM, et al. Abnormal surface liquid $\mathrm{pH}$ regulation by cultured cystic fibrosis bronchial epithelium. Proc Natl Acad Sci U S A. 2003; 100:16083-16088. [PubMed: 14668433]

Delacourt C, Herigault S, Delclaux C, Poncin A, Levame M, Harf A, et al. Protection against acute lung injury by intravenous or intratracheal pretreatment with EPIHNE-4, a new potent neutrophil elastase inhibitor. Am J Respir Cell Mol Biol. 2002; 26:290-297. [PubMed: 11867337]

Di YP. Functional roles of SPLUNC1 in the innate immune response against Gram-negative bacteria. Biochem Soc Trans. 2011; 39:1051-1055. [PubMed: 21787346]

Di YP, Harper R, Zhao Y, Pahlavan N, Finkbeiner W, Wu R. Molecular cloning and characterization of spurt, a human novel gene that is retinoic acid-inducible and encodes a secretory protein specific in upper respiratory tracts. J Biol Chem. 2003; 278:1165-1173. [PubMed: 12409287]

Donaldson SH, Hirsh A, Li DC, Holloway G, Chao J, Boucher RC, et al. Regulation of the epithelial sodium channel by serine proteases in human airways. J Biol Chem. 2002; 277:8338-8345. [PubMed: 11756432]

Fahy JV, Dickey BF. Airway mucus function and dysfunction. N Engl J Med. 2010; 363:2233-2247. [PubMed: 21121836]

Feng W, Nakamura S, Sudo E, Lee MM, Shao A, King M. Effects of dextran on tracheal mucociliary velocity in dogs in vivo. Pulm Pharmacol Ther. 1999; 12:35-41. [PubMed: 10208834]

Gaillard EA, Kota P, Gentzsch M, Dokholyan NV, Stutts MJ, Tarran R. Regulation of the epithelial Na + channel and airway surface liquid volume by serine proteases. Pflugers Arch. 2010; 460:1-17. [PubMed: 20401730]

Gally F, Di YP, Smith SK, Minor MN, Liu Y, Bratton DL, et al. SPLUNC1 promotes lung innate defense against Mycoplasma pneumoniae infection in mice. Am J Pathol. 2011; 178:2159-2167. [PubMed: 21514430]

Garcia-Caballero A, Rasmussen JE, Gaillard E, Watson MJ, Olsen JC, Donaldson SH, et al. SPLUNC1 regulates airway surface liquid volume by protecting $\mathrm{ENaC}$ from proteolytic cleavage. Proc Natl Acad Sci U S A. 2009; 106:11412-11417. [PubMed: 19541605]

Garland AL, Walton WG, Coakley RD, Tan CD, Gilmore RC, Hobbs CA, et al. Molecular basis for pH-dependent mucosal dehydration in cystic fibrosis airways. Proc Natl Acad Sci U S A. 2013; 110:15973-15978. [PubMed: 24043776]

Gentzsch M, Dang H, Dang Y, Garcia-Caballero A, Suchindran H, Boucher RC, et al. The cystic fibrosis transmembrane conductance regulator impedes proteolytic stimulation of the epithelial $\mathrm{Na}$ + channel. J Biol Chem. 2010; 305:L990-L1001.

Gibson RL, Burns JL, Ramsey BW. Pathophysiology and management of pulmonary infections in cystic fibrosis. Am J Respir Crit Care Med. 2003; 168:918-951. [PubMed: 14555458]

Hobbs CA, Blanchard MG, Alijevic O, Tan CD, Kellenberger S, Bencharit S, et al. Identification of SPLUNC1's ENaC-inhibitory domain yields novel strategies to treat sodium hyperabsorption in cystic fibrosis airway cultures. Am J Physiol Lung Cell Mol Physiol. 2013

Hughey RP, Carattino MD, Kleyman TR. Role of proteolysis in the activation of epithelial sodium channels. Curr Opin Nephrol Hypertens. 2007; 16:444-450. [PubMed: 17693760]

Iwao K, Watanabe T, Fujiwara Y, Takami K, Kodama K, Higashiyama M, et al. Isolation of a novel human lung-specific gene. LUNX, a potential molecular marker for detection of micrometastasis in non-small-cell lung cancer. Int J Cancer. 2001; 91:433-437. [PubMed: 11251963] 
Jiang D, Wenzel SE, Wu Q, Bowler RP, Schnell C, Chu HW. Human neutrophil elastase degrades SPLUNC1 and impairs airway epithelial defense against bacteria. PLoS ONE. 2013; 8:e64689. [PubMed: 23741370]

Kerem E, Bistritzer T, Hanukoglu A, Hofmann T, Zhou Z, Bennett W, et al. Pulmonary epithelial sodium-channel dysfunction and excess airway liquid in pseudohypoaldosteronism. N Engl J Med. 1999; 341:156-162. [PubMed: 10403853]

Kesimer M, Kirkham S, Pickles RJ, Henderson AG, Alexis NE, Demaria G, et al. Tracheobronchial air-liquid interface cell culture: a model for innate mucosal defense of the upper airways? Am J Physiol Lung Cell Mol Physiol. 2009; 296:L92-L100. [PubMed: 18931053]

Kim SH, Marcus DC. Regulation of sodium transport in the inner ear. Hear Res. 2011; 280:21-29. [PubMed: 21620939]

Knowles MR, Boucher RC. Mucus clearance as a primary innate defense mechanism for mammalian airways. J Clin Invest. 2002; 109:571-577. [PubMed: 11877463]

Knowles MR, Robinson JM, Wood RE, Pue CA, Mentz WM, Wager GC, et al. Ion composition of airway surface liquid of patients with cystic fibrosis as compared with normal and disease-control subjects. J Clin Invest. 1997; 100:2588-2595. [PubMed: 9366574]

Konstan MW, Hilliard KA, Norvell TM, Berger M. Bronchoalveolar lavage findings in cystic fibrosis patients with stable, clinically mild lung disease suggest ongoing infection and inflammation. Am J Respir Crit Care Med. 1994; 150:448-454. [PubMed: 8049828]

Mall M, Grubb BR, Harkema JR, O’Neal WK, Boucher RC. Increased airway epithelial Na+ absorption produces cystic fibrosis-like lung disease in mice. Nat Med. 2004; 10:487-493. [PubMed: 15077107]

Matsui H, Grubb BR, Tarran R, Randell SH, Gatzy JT, Davis CW, et al. Evidence for periciliary liquid layer depletion, not abnormal ion composition, in the pathogenesis of cystic fibrosis airways disease. Cell. 1998; 95:1005-1015. [PubMed: 9875854]

McGillivary G, Bakaletz LO. The multifunctional host defense peptide SPLUNC1 is critical for homeostasis of the mammalian upper airway. PLoS ONE. 2010; 5:e13224. [PubMed: 20949060]

Poulsen JH, Fischer H, Illek B, Machen TE. Bicarbonate conductance and pH regulatory capability of cystic fibrosis transmembrane conductance regulator. Proc Natl Acad Sci U S A. 1994; 91:53405344. [PubMed: 7515498]

Rollins BM, Garcia-Caballero A, Stutts MJ, Tarran R. SPLUNC1 expression reduces surface levels of the epithelial sodium channel (ENaC) in Xenopus laevis oocytes. Channels (Austin). 2010; 4:255259. [PubMed: 20519934]

Rossier BC, Stutts MJ. Activation of the epithelial sodium channel (ENaC) by serine proteases. Annu Rev Physiol. 2008

Roxo-Rosa M, da Costa G, Luider TM, Scholte BJ, Coelho AV, Amaral MD, et al. Proteomic analysis of nasal cells from cystic fibrosis patients and non-cystic fibrosis control individuals: search for novel biomarkers of cystic fibrosis lung disease. Proteomics. 2006; 6:2314-2325. [PubMed: 16518875]

Tarran R, Grubb BR, Gatzy JT, Davis CW, Boucher RC. The relative roles of passive surface forces and active ion transport in the modulation of airway surface liquid volume and composition. J Gen Physiol. 2001a; 118:223-236. [PubMed: 11479349]

Tarran R, Grubb BR, Parsons D, Picher M, Hirsh AJ, Davis CW, et al. The CF salt controversy: in vivo observations and therapeutic approaches. Mol Cell. 2001b; 8:149-158. [PubMed: 11511368]

Tarran R, Trout L, Donaldson SH, Boucher RC. Soluble mediators, not cilia, determine airway surface liquid volume in normal and cystic fibrosis superficial airway epithelia. J Gen Physiol. 2006; 127:591-604. [PubMed: 16636206]

Welsh MJ, Smith AE. Molecular mechanisms of CFTR chloride channel dysfunction in cystic fibrosis. Cell. 1993; 73:1251-1254. [PubMed: 7686820]

Weston WM, LeClair EE, Trzyna W, McHugh KM, Nugent P, Lafferty CM, et al. Differential display identification of plunc, a novel gene expressed in embryonic palate, nasal epithelium, and adult lung. J Biol Chem. 1999; 274:13698-13703. [PubMed: 10224143] 
Worlitzsch D, Tarran R, Ulrich M, Schwab U, Cekici A, Meyer KC, et al. Effects of reduced mucus oxygen concentration in airway Pseudomonas infections of cystic fibrosis patients. J Clin Invest. 2002; 109:317-325. [PubMed: 11827991]

Zhang B, Nie X, Xiao B, Xiang J, Shen S, Gong J, et al. Identification of tissue-specific genes in nasopharyngeal epithelial tissue and differentially expressed genes in nasopharyngeal carcinoma by suppression subtractive hybridization and cDNA microarray. Genes Chromosomes Cancer. 2003; 38:80-90. [PubMed: 12874788]

Zhou HD, Li XL, Li GY, Zhou M, Liu HY, Yang YX, et al. Effect of SPLUNC1 protein on the Pseudomonas aeruginosa and Epstein-Barr virus. Mol Cell Biochem. 2008; 309:191-197. [PubMed: 18049866] 


\section{A \\ 1 MFQTGGLIVFYGLLAQTMAFGGLPVPLDQTLPLNVNPALPLSPTGLAGSLTNALSNGLL 60 SGGLLGILENLPLLDILKPGGGTSGGLLGGLLGKVTSVIPGLNNI IDIKVTDPQLLELGL 120 VQSPDGHRLYVTIPLGIKLQVNTPLVGASLLRLAVKLDITAEILAVRDKQERIHLVLGDC 180 THSPGSLQISLLDGLGPLPIQGLLDSLTGILNKVLPELVQGNVCPLVNEVLRGLDITLVH 240 DIVNMLIHGLQFVIKV}

B

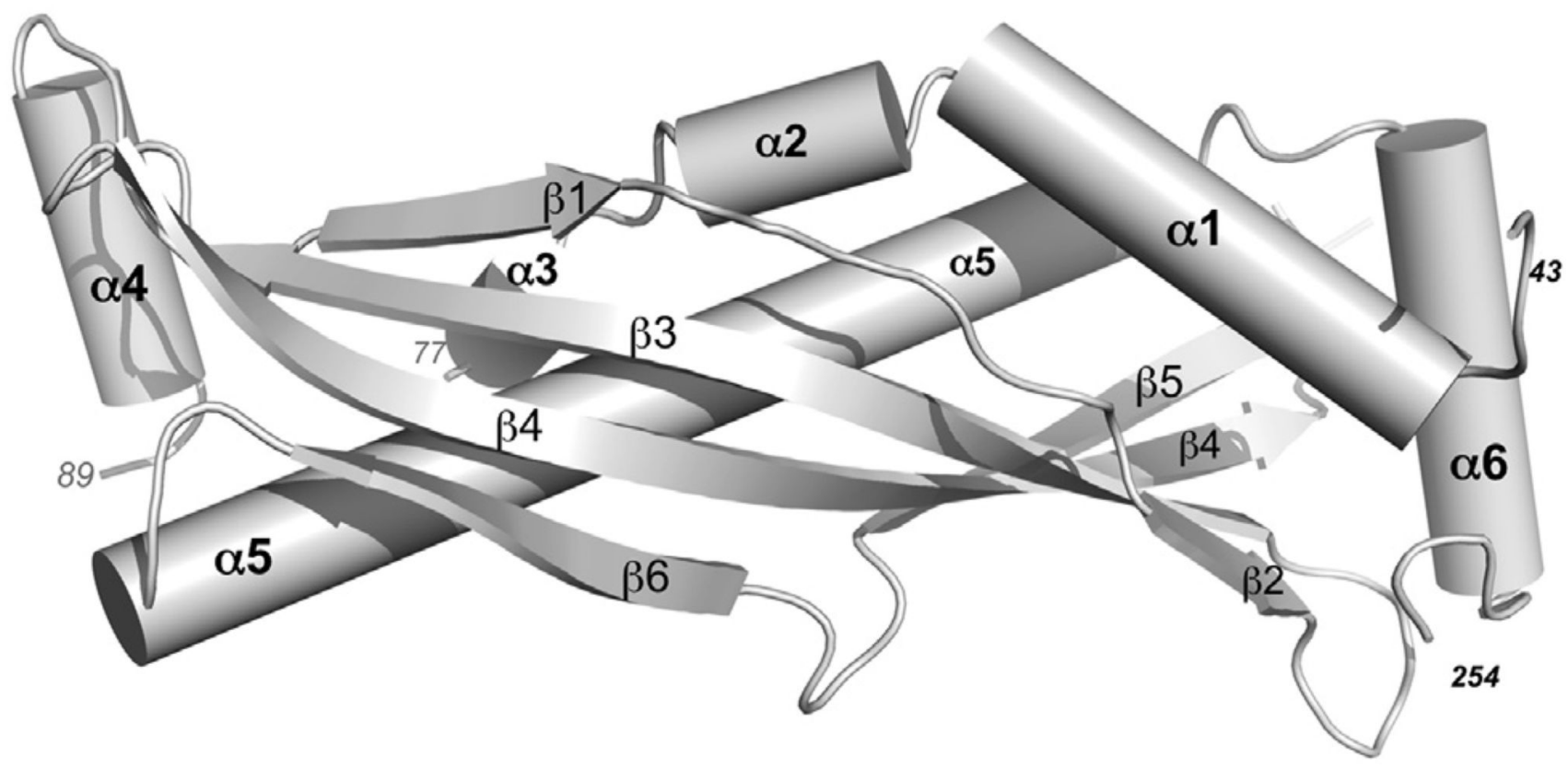

Fig. 1.

SPLUNC1 amino acid sequence and crystal structure. (A) The cleaved leader sequence is highlighted gray. The ENaC inhibitory domain (a.k.a. the S18 region) is highlighted in yellow. Basic (blue) and acidic (red) residues known to confer $\mathrm{pH}$-sensitivity on SPLUNC1 are shown in bold. The underlined pair of residues constitute one potential salt bridge while the second set of residues constitute a second salt bridge. (B) Ribbon diagram of the crystal structure of human SPLUNC1. 

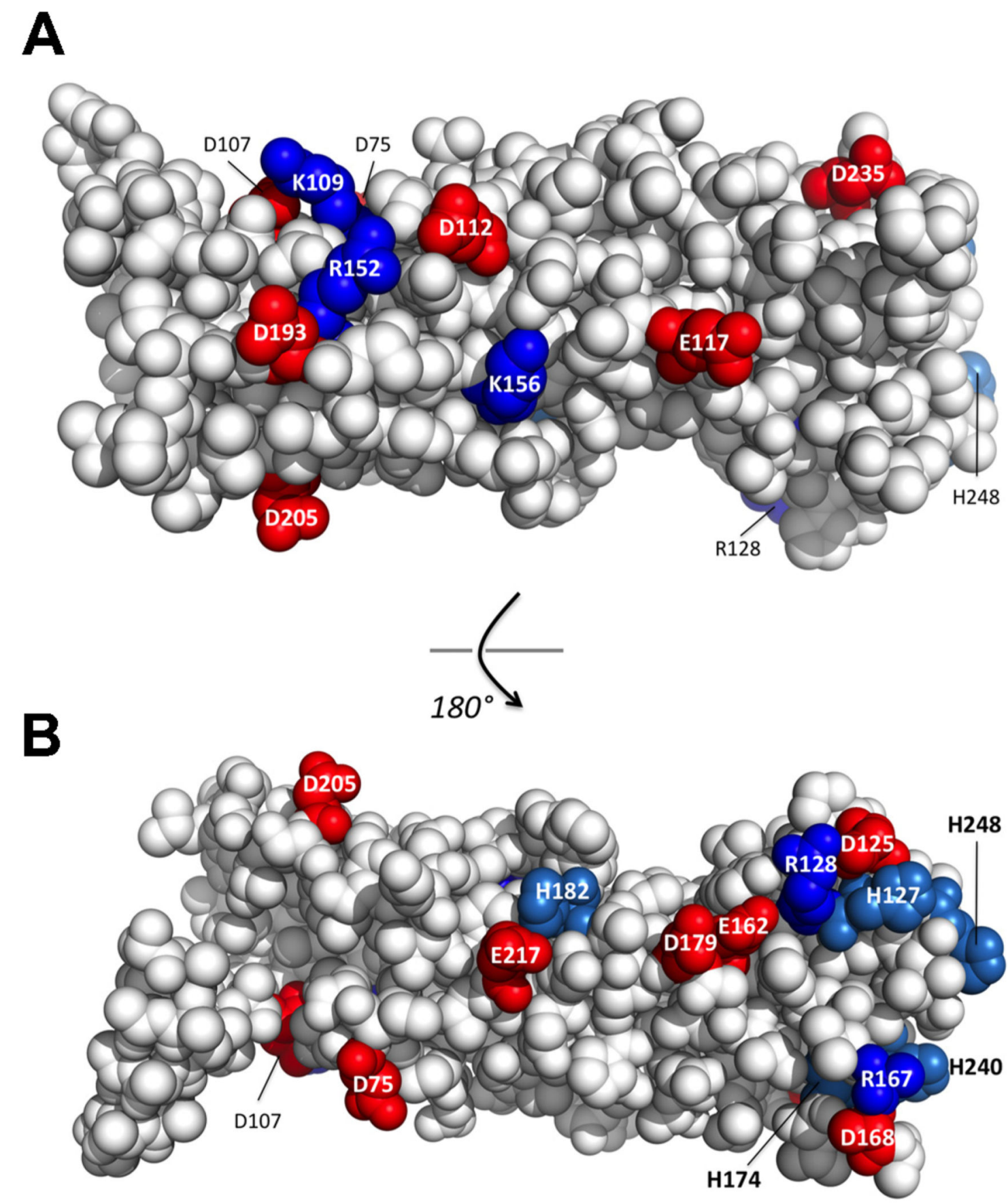

Fig. 2.

Conserved electrostatic residues on the surface of SPLUNC1. (A) Conserved electrostatic residues on SPLUNC1 as shown in panel A. (B) Conserved electrostatic residues on the opposite side of SPLUNC1 as indicated. Acidic residues are shown in red while basic residues are shown in blue. (For interpretation of the references to color in this figure legend, the reader is referred to the web version of the article.) 


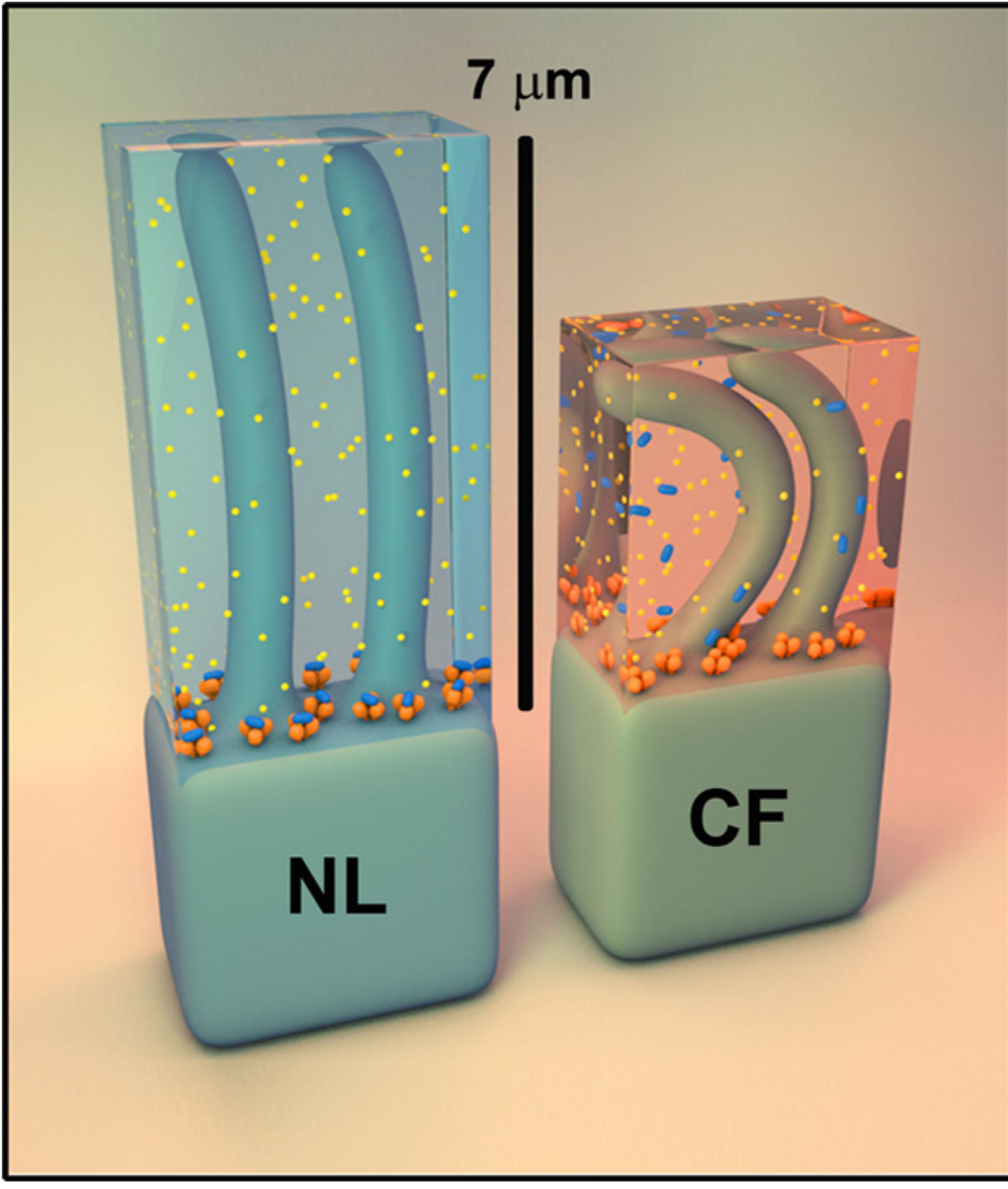

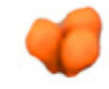 $\mathrm{NaCl}$} $\alpha \beta \gamma$ ENaC SPLUNC1

Fig. 3.

Schematic of airway surface liquid (transparent blue or red) above ciliated epithelial cells as depicted for normal lung (NL, left) and cystic fibrosis ( $\mathrm{CF}$, right) lung. The heterotrimeric epithelial sodium channel $(\mathrm{ENaC})$ is rendered in orange, soluble SPLUNC1 in blue, and sodium ions as yellow. In normal (NL) airways, SPLUNC1 binds to and regulates ENaC, keeping a healthy level of sodium and water that allows cilia to function. In CF, low fluid $\mathrm{pH}$ prevents SPLUNC1's regulation of $\mathrm{ENaC}$, allowing isotonic removal of sodium and water by this channel, dehydrating the ASL and significantly reducing cilia function. (For interpretation of the references to color in this figure legend, the reader is referred to the web version of the article.) 